\title{
Ontic Injustice
}

\begin{abstract}
In this paper, I identify a distinctive form of injustice - 'ontic injustice in which an individual is wronged by the very fact of being socially constructed as a member of a certain social kind. To be a member of a certain social kind is, at least in part, to be subject to certain social constraints and enablements, and these constraints and enablements can be wrongful to the individual who is subjected to them, in the sense that they inflict a moral injury. The concept of ontic injustice is valuable in three main ways: it draws our attention to the role played by social kinds in enacting wrongful constraints and enablements; it clarifies our options for developing accounts of the ontology of particular social kinds, such as gender kinds; and - along with the related concept of 'ontic oppression' - it helps us to understand and respond to oppression.
\end{abstract}

Key Words: Social Construction, Injustice, Moral Injury, Social Kinds, Gender Kinds

Katharine Jenkins, Department of Philosophy, University of Nottingham

krcjenkins@gmail.com

\section{Introduction ${ }^{1}$}

In recent years, a number of important contributions to moral, social, and political philosophy have identified distinctive forms of injustice that had not previously been explicitly defined. These have concerned phenomena such as knowledge for example, Miranda Fricker's (2007) account of 'epistemic injustice' - and

\footnotetext{
1 This paper began life as part of my (2016) PhD thesis of the same title, which benefitted enormously from the wise guidance of my supervisors, Jennifer Saul and Miranda Fricker, and the generous comments of Rae Langton, my external examiner. I have presented versions of this paper at seminars at the University of Cambridge, the University of Nottingham, the University of Edinburgh, and the University of Glasgow, and at conferences including Non-Ideal Social Ontology I (University of Stockholm), Defective Concepts (University of Leeds), and Social Ontology 2018 (Tufts University); I am grateful to the audiences at each of these events for stimulating discussions. I thank the following people for their detailed comments on the whole paper: Ásta, Johan Brännmark, Åsa Burman, Arto Laitinen, Kate Ritchie, and Aness Webster. Finally, I thank two anonymous referees for this journal for their extremely constructive comments, which materially improved the paper.
} 
communication - for example, Rebecca Kukla's (2014) account of 'discursive injustice'. In this paper, I identify a distinctive form of injustice that concerns the social construction of human kinds. I show that an individual can be wronged by the very fact of being socially constructed as a member of a certain social kind kinds such as wife, slave, woman, black person. Since this wrong operates through social ontology, I term it 'ontic injustice'. I hope to show that ontic injustice is a distinctive, pervasive, and interesting type of injustice which merits attention from moral, social, and political theorists.

I will begin by showing that there is an implicit consensus among different accounts of social ontology that what it is to be a member of a certain social kind is, at least in part, to be subject to certain social constraints and enablements. I will then offer a definition of ontic injustice, explain the nature of the wrong it involves, show how the concept can be applied to particular cases, and demonstrate what we stand to gain from incorporating ontic injustice into our conceptual repertoire.

\section{Constraints and Enablements in Accounts of Social Ontology}

Many prominent accounts of the ontology of social kinds explicitly hold that being a certain kind of social entity is, in some sense, a matter of being subject to certain social constraints and enablements. Probably the most well-known example of this is Searle's account of institutional facts $(1996 ; 2011)$. Searle focuses on those social facts which are the products of human institutions, such the facts that certain people are husbands, judges, and presidents. He holds that in order for it to be a social fact that some individual is a husband, a judge or a president, that individual must have certain 'conventional deontic powers'. Conventional deontic powers are socially created permissions, duties, and so on that an individual has in dependence upon collective intentionality. If members of a society collectively recognise people who have been through a certain ceremony (a marriage, a swearing in) as having the powers associated with being a husband, a judge or a president, then this is what makes it the case that certain people are husbands, judges and presidents.

Another view that explicitly focuses on constraints and enablements is Ásta's (2018) account of social properties as conferred properties. Ásta's view is somewhat different from Searle's, since she is not only concerned with institutional kinds, but with more informal social kinds, which she terms 'communal' kinds. According to Ásta, to be a particular sort of social entity is to have a certain status conferred upon you by relevant other social agents, where this status consists of particular constraints and enablements. For example, you might have the status 'woman' conferred on you in a cocktail bar, where this means that you can expect that men will buy you a drink if they wish to make conversation 
with you, and that you are expected to dress in a certain way and to respond politely to overtures from strange men (unless you are already talking to a man). Having the status 'woman' conferred on you at a family party, or in a workplace, would involve different constraints and enablements. Moreover, when other agents confer the status on you, they typically take themselves to be tracking something about you. This 'base property' can also vary from context to context. In some social locations it may be genital status, in others, legal sex, and in others, self-identification as a woman. As should be apparent, on this view social kind properties are radically context-dependent. On Ásta's view, the social property consists of a conferred social status, and the social status in turn consists of constraints and enablements. Thus, being a member of a certain social kind consists of being subject to the relevant constraints and enablements.

There are other accounts of the ontology of social kinds that do not explicitly equate being a member of a social kind with being subject to social constraints and enablements. Nevertheless, many of these accounts implicitly allocate a similar role to constraints and enablements. For example, some accounts focus on equilibria in social behaviour (Calvert 1998; Greif and Kingston 2011). Finding oneself in a situation of social equilibrium, in which no-one can unilaterally deviate from a pattern of behaviour without making themselves worse off, necessarily means being constrained: the available options and outcomes have been altered by the social co-ordination, and some possibilities (deviating and benefitting from doing so) are ruled out. ${ }^{2}$

Other accounts focus on causal patterns and predictive power. Here, too, we find constraints and enablements playing an important, though tacit, role. Consider Ron Mallon's (2016) account of certain human social kinds, which equates these kinds with homeostatic property clusters, described by Mallon as 'clusters of nonaccidentally co-occurring properties that sustain explanatory and practical projects including prediction, explanation, and intervention' (2016: 69). These clusters are the result of co-ordinated behaviours prompted and organised by commonly understood conceptions of social roles. Races and genders are, Mallon argues, human social kinds of this sort: shared ideas about race and gender prompt people to behave in patterned ways, and this makes certain outcomes more or less likely for people who have been categorised a particular way with regard to race or gender. Here, too, constraints and enablements are implicitly in the picture, because in order for there to be patterns of outcomes that can support predictive power, it must be made harder or easier for people to do certain things. For example, if gender serves to predict earnings, then it must be the case that social

${ }^{2}$ See Guala and Hindriks (2015) for an interesting model that unifies rules-focused accounts (such as Searle's) and equilibria-focused accounts. 
practices surrounding gender roles have made it harder (in some sense or other) for women than for men to earn high wages.

I do not claim that all accounts of the ontology of social kinds entail that social constraints and enablements constitute (at least partly) membership in social kinds. ${ }^{3}$ Rather, I claim that there is an implicit consensus to this effect: most accounts of the ontology of social kinds either directly hold or indirectly imply that social constraints and enablements at least partly constitute social kind membership. In what follows, I will assume a view of the ontology of social kinds that accords with this consensus.

\section{Defining Ontic Injustice}

The phenomenon that I want to pick out with the label 'ontic injustice' concerns the constraints and enablements that constitute social kind membership. The thought is that in some cases, these constraints and enablements may be wrongful, in the sense that they are in contravention of the individual's moral entitlements.

As an example of this phenomenon, consider the situation of wives in England and Wales prior to 1991, which is when the marital rape exemption was ended in these countries. Prior to 1991, if a husband had sex with his wife without her agreement, including by force, this did not constitute rape in the eyes of the law, as it was deemed that in getting married the wife had consented in perpetuity to sex with her husband. Accordingly, an individual socially constructed as a wife lacked the social entitlement to refuse to have sex with her husband. According to many accounts of social ontology, including Searle's and Ásta's, what it was to be a wife in England and Wales prior to 1991 was, in part, to be someone who was not socially entitled to control fully sexual access to one's own body. This state of affairs is clearly morally wrong: everyone is morally entitled to control fully sexual access to their own body. Accordingly, there is a profound mis-match between the moral entitlements of the individuals who were wives, and the social constraints and entitlements that constituted the social kind wife. It is this mis-match which I think is a distinctive type of moral wrong affecting those socially constructed as wives at that time, and which I aim to capture with the concept of ontic injustice.

It is important to be clear from the beginning about what ontic injustice is not. Ontic injustice is not the harm that occurs when individuals actually act in accordance with the relevant constraints and enablements. For instance, in the example of wives in England and Wales prior to 1991, ontic injustice is distinct from the harm of a wife actually being raped by her husband. Furthermore, ontic

\footnotetext{
${ }^{3}$ For an account that is consistent with the rejection of the claim that constraints and enablements constitute (at least partly) membership in social kinds, see Ritchie (2018).
} 
injustice is not the same as the psychological damage that may arise from a person's being aware of the wrongful constraints and enablements, which is part of what has been termed 'psychological oppression' (see, for example, Fanon 2008; Bartky 1979). Staying with the example of wives, we may imagine that a wife who was aware of the fact that she had no legal protection against being raped by her husband might well have found this thought distressing, and might also have suffered, for example, damage to her self-esteem. She may even have come to believe that she did not deserve to be able to fully control sexual access to her own body. Any of these psychological effects constitutes a serious harm, but none of these harms is what I am aiming to capture with the idea of ontic injustice.

Rather, the wrong on which I am interested is the mere fact that an individual is a certain kind of social being, where what it means to be that kind of social being is to be subject to morally inappropriate constraints and enablements. In the example concerning the marital rape exemption, the ontic injustice is the mere fact that someone is a wife, where being a wife consists, at least in part, of being someone who is not entitled to control fully sexual access to one's own body. A wife who is not raped by her husband and who suffers no psychological harm from knowing about the marital rape exemption still suffers ontic injustice. ${ }^{4}$ Ontic injustice, then, is a wrong at the level of being which affects every member of the social kind in question, regardless of their specific experiences.

Here is a definition of ontic injustice:

Ontic injustice: An individual suffers ontic injustice if and only if they are socially constructed as a member of a certain social kind where that construction consists, at least in part, of their being subjected to a set of social constraints and enablements that is wrongful to them.

For instance, in England and Wales prior to 1991 the social kind wife was a site of ontic injustice because the marital rape exemption meant that being a member of the social kind wife consisted in part of lacking the social entitlement to control fully sexual access to one's own body. This constraint was wrongful to those individuals who were socially constructed as wives because it removed their social entitlement to do something that they were morally entitled to do (namely, to control fully sexual access to their own body).

Note that the definition specifies that the set of constraints and enablements must be wrongful to the individual in question. This is important, because social constraints and enablements are relational: my being under a certain social constraint, say, not to take your wallet from your pocket, means that you have a certain social enablement, in this case an enablement to retain your wallet in your

${ }^{4}$ There is a parallel here with accounts of freedom as non-domination: a person is dominated if they are vulnerable to the arbitrary interference of another, even if that interference never takes place (Pettit 1996). 
pocket. ${ }^{5}$ It follows that a person being subject to a wrongful constraint will mean that others are subject to corresponding enablements that are likewise wrongful. These corresponding enablements are wrongful, but they are not wrongful to the individual who has them, but rather to other individuals. For example, in England and Wales prior to 1991, a husband had the social enablement to have sex with his wife whenever he wanted regardless of whether she agreed to the sex. The husband's set of constraints and enablements was therefore wrongful, but it was not wrongful to the husband, but rather to the wife. Therefore, the category of husband, although it involved a wrongful set of constraints and enablements, was not a site of ontic injustice.

One question that might arise about the definition of ontic injustice that I have offered is this: why does the definition refer to constraints and enablements, when surely only constraints can prevent people from doing or receiving what they are morally entitled to do or receive? ${ }^{6}$ The answer is that I take it that sometimes enablements can indirectly prevent individuals from doing or receiving what they are morally entitled to do or to receive. One way this can happen is if the enablements create a pressure to act in a certain way, depriving the person of choices to which they were entitled. For example, consider a case in which mothers, but not fathers, are entitled to take time off from paid work to look after children. This might result in mothers feeling obliged to take time off from paid work, because there are no good alternatives, and in their being judged negatively if they do not take time off from paid work. As a consequence, mothers' ability to choose how to arrange their lives is compromised and they may have reduced access to goods associated with paid work. Now, on some accounts of social ontology, this case would count as one in which mothers are under a constraint regarding their careers. If we confined our attention to those views, then we would be able to account for this case purely in terms of wrongful constraints. However, on other views, such as Searle's, mothers would not count as being under a constraint, because there is no formal, collectively recognised duty for mothers to take time off from paid work - merely a prerogative to take time off (which is not shared by fathers). Therefore, the possibility of wrongful enablements must be kept open in order to make the definition of ontic injustice fit with any account of social ontology. Note, too, that the definition refers to a 'wrongful set of constraints and enablements'. This allows for the possibility that a certain combination of constraints and enablements may prevent an individual from doing or receiving what they are morally entitled to do or to receive, even if no single constraint or enablement would have this effect by itself.

\footnotetext{
${ }^{5}$ Brännmark (2018) offers a helpful account of this relationality in terms of Hohfeldian incidents. ${ }^{6}$ I thank Kate Ritchie for bringing this question to my attention.
} 


\section{The Wrong of Ontic Injustice}

The idea of a wrong that consists of being subject to morally inappropriate constraints and enablements serves to give an initial fix on the phenomenon that I want to identify as ontic injustice. However, the question then arises: what exactly does this wrong consist of? Being under a morally inappropriate set of constraints and enablements, such that other agents are socially licensed to treat one in morally impermissible ways, will typically raise the risk that such treatment, with the attendant material and psychological harms, will occur. For example, the existence of a marital rape exemption will usually mean that wives are at greater risk of being raped by their husbands, and also at greater risk of suffering psychological harms as a result of their awareness of this vulnerability. We tend to think that being placed at risk of harm can be wrongful in itself, as when someone is on the receiving end of irresponsible medical practice, but, due to sheer luck, does not sustain physical injury. So risk offers one way of understanding the wrong of ontic injustice. Yet I want to suggest that, as well as risk, being placed under a morally inappropriate set of constraints and enablements involves a further harm, one that Jean Hampton has termed 'moral injury', and which is understood roughly as an 'affront to value or dignity' (Hampton 1991: 1666).

Hampton notes that the ways in which agents behave towards each other can convey meaning: by turning my back on you when you try to speak, for instance, I convey something about my attitude to you and to your attempt to speak in this context. Sometimes, the meaning of a certain behaviour enacts what Hampton terms 'diminishment', which is the appearance that a person's value has been lowered. For example, violence inflicted on a person in a deliberately humiliating way not only harms the person materially and psychologically, but conveys the impression that the person lacks the kind of value that should properly be attributed to people. 'Diminishment', Hampton writes, 'is an "objective" phenomenon, by which I merely mean... that it is not something that can be identified with any psychological experience of victimization. Instead, it is something that we "read off" the effects of immoral behaviour' (1991: 1674) Moreover, Hampton stresses that diminishment is not an actual reduction in moral worth, but rather the appearance of a reduction in moral worth. The person who is subject to a deliberately humiliating violent attack does not actually come to have lower moral worth as a consequence; rather, the way they are treated gives the false impression that they have lower moral worth than they really do.

Diminishment in turn, Hampton argues, causes damage to either the realization or the acknowledgement of a person's value. Damage to the realization of value occurs when actual treatment takes place which is contrary to the entitlements someone has in virtue of her moral value. Damage to the acknowledgement of value occurs when someone is represented as having less moral value than she in 
fact has; for example, an unsuccessful attempt to inflict humiliating violence on someone still conveys the impression that this form of treatment would have been appropriate, and hence that she has a lower moral value than she in fact has. If either form of damage to value occurs, the victim has suffered moral injury. Thus Hampton defines moral injury as 'damage to the realization of a victim's value, or damage to the acknowledgement of the victim's value, accomplished through behaviour whose meaning is such that the victim is diminished in value' (1991: 1679, italics in original).

In articulating the idea of moral injury, Hampton relies on the claim that most of us do in fact operate with some conception of the moral worth of human beings, which is to say, some 'beliefs about how human beings are to be valued, and how to appraise each individual's value' (1991: 1666). For this reason, Hampton contends, we should care about the damage to the realization or acknowledgement of a person's value that is caused by diminishment:

I cannot explain that offensiveness [of damage to the realization or acknowledgement of value] by appealing to something else, because it is the foundation of our objection to wrongdoing; it is part of what it means to say that something is valuable that we ought to care about preserving and acknowledging that value. (1991: 1684)

Thus, the concept of moral injury does not supply an account of the moral worth of human beings that we should be concerned to protect from damage - of what such worth is based on, why we should care about it, and so on. Rather, the concept of moral injury identifies a form of injury or wrong that anyone who already subscribes to an account of the moral worth of human beings should acknowledge, basing her judgements about putative cases of moral injury on her prior commitments concerning the moral worth of human beings. ${ }^{7}$ The concept of moral injury therefore relies on a modest metaethical commitment: one must not hold a conception of the value of different sorts of beings according to which an individual's moral worth is entirely set by how they are socially represented, because such a conception would imply that it is impossible for an individual's moral worth to be wrongly represented as lower than it in fact is. There needs to be some gap between actual moral worth and social representation of moral worth in order for the concept of moral injury to get off the ground.

Importantly for our purposes, although moral injury is related to the risk of material or psychological harm, it is not identical with such risk. For example, noting that books advancing racist and sexist worldviews can cause moral injury, Hampton writes: 'such books morally injure not one individual, but a whole class of individuals, leaving them sitting ducks for treatment lower (perhaps much lower) than that which they deserve' (1991: 1679). However, moral injury is

${ }^{7}$ I will return to this point in $\S 5$ below. 
defined not merely as risk (being made into a 'sitting duck'), but as actual damage. Moral injury brings with it a risk of damage to material and psychological wellbeing, but what it consists of is actual damage to the realization or acknowledgement of value.

The concept of moral injury captures the wrong of ontic injustice. When someone is subject to constraints and enablements that license treatment that falls far short of the sort of treatment to which she is morally entitled, she suffers a moral injury, one that takes the form of damage to the acknowledgement of her value. This damage is an additional wrong over and above the wrong of being placed at risk of material and psychological harm. Someone who is socially constructed as a wife in the context of a marital rape exemption has been represented as having less moral value than she in fact has, suffering damage to the acknowledgement of her value that constitutes a moral injury. However, there are two ways in which I need to slightly adapt Hampton's account of moral injury presentation in order to make it better fit my purposes.

First, Hampton emphasizes 'behaviour' and seems mostly to be thinking about cases where an agent A behaves a certain way towards another agent, B, causing B to suffer diminishment. This makes sense within the context of Hampton's larger project, which concerns theories of punishment. ${ }^{8}$ The problem here is that it does not make sense to think of an individual's being socially constructed as a member of a certain kind as something that is enacted through the behaviour of one single other agent. Even in cases where a particular agent plays an important role - the officiant in a marriage ceremony, say - the maintenance of a social ontology requires the participation of many others as well, and this participation is often cashed out in terms of their attitudes rather than specific actions. However, there is nothing in the notion of moral injury itself that necessitates an interpersonal focus. The wrong that a person suffers when they suffer a moral injury is the actual damage to the realization or acknowledgement of their value. From the victim's perspective, this damage can be the same, whether it is inflicted directly by one individual or via more diffuse mechanism. I will therefore think of moral injury as accomplished through treatment than through behaviour, where interpersonal behaviour is just one form of treatment. Someone who has been socially constructed as a member of a certain human kind has been on the receiving end of a form of treatment, even though this treatment cannot usually be equated with the behaviour of a specific individual. What matters is that the treatment is the product of human social arrangements, and therefore falls within the scope of considerations of justice, rather than being the product of natural

${ }^{8}$ Specifically, she argues that it is because punishable behaviour enacts moral injury that retributive responses can be appropriate: retributive punishment can cancel out the diminishment by reaffirming the victim's moral worth. I take no stance on this application of the concept of moral injury. 
forces. This last point is important. Categories which are not socially constructed cannot be sites of ontic injustice, because they are not the sort of thing that can be appropriately considered to be just or unjust.

The second adaptation I need to make to Hampton's account of moral injury concerns her focus on human beings. Again, this makes sense in the context of a discussion of punishment. But in fact, there is no general reason to limit the scope of moral injury to human beings. The concept of moral injury relies on a prior notion of a conception of the moral worth of human beings, and it is true that such conceptions loom particularly large in our moral landscape. However, it is perfectly possible to have a conception of the moral worth of beings of other sorts - 'sentient beings', for example - and many people do seem to hold such conceptions. Such conceptions can function as the basis of a judgement of moral injury just as well as conceptions of human value. I do not claim that everyone in fact holds conceptions of the moral worth of broader classes of beings beyond human beings, nor do I here wish to defend the claim that some such conceptions are warranted. I simply note that such conceptions will serve perfectly well as support for judgements about moral injury, and, for this reason, I will not take the notion of moral injury to apply solely to human beings, but treat it as applicable to any sort of being that may be the subject of a conception of value. ${ }^{9}$

There is a close connection between Hampton's account of moral injury and Stephen Darwall's (1977) account of 'recognition respect'. ${ }^{10}$ According to Darwall, there are two quite different attitudes that go by the name of 'respect'. On the one hand, 'appraisal respect' is a positive evaluation of a person; this is the sort of respect involved in respecting someone as a sportsperson, or as a philosopher. Appraisal respect can be withdrawn, for example if one learns that one's favourite sportsperson has been taking performance enhancing drugs, or that one's favourite philosopher is a serial plagiarist. Recognition respect, on the other hand, is a matter of recognizing certain properties of someone or something, and being disposed to respond appropriately to these. This is the attitude involved in respecting someone as a person, or in respecting a work of art. We recognize that the person has certain morally relevant properties that mean that we ought not to harm her, exploit her and so on. Similarly, we recognize that the work of art has aesthetic value, and we ought not to wantonly destroy or damage it. Unlike appraisal respect, recognition respect cannot legitimately be withdrawn; even someone who has forfeited our appraisal respect as a sportsperson still has a claim to our recognition respect as a person.

\footnotetext{
${ }^{9}$ This distinguishes my use of the concept of moral injury from, for example, Mari Mikkola's (2016) use of it in her account of dehumanization.

${ }^{10}$ Another related concept is that of a 'dignitary harm' (Waldron 2014), and there are also links to Darwall's work on dignity (2004).
} 
Darwall further identifies a sub-category of recognition respect, moral recognition respect, in which the properties in question are morally relevant. The case of respecting the person is a case of moral recognition respect, whereas the case of respecting the painting is not. There is a strong relationship between failures of recognition respect and moral injuries. When a failure of moral recognition respect occurs, the individual towards whom the respect was owed suffers a moral injury, because damage has been done to the acknowledgement of their value. Moral injury is a more direct way of spelling out the wrong of ontic injustice, because it places the focus on what has happened to the individual who has been wronged, not on the attitude by means of which the wrong was enacted. However, the notion of recognition respect enriches our understanding of how moral injury is enacted, and, in particular, is useful in that it highlights the idea of a mis-match between moral entitlements, on the one hand, and social entitlements, on the other. When ontic injustice occurs, there has been a social failure to respond appropriately to the morally relevant properties of the individual in question, and it is this failure that enacts diminishment, the impression that the person's moral value is less than it really is. In identifying cases of ontic injustice, then, we should be on the look out for instances of mis-match between moral and social entitlements, as highlighted by the idea of recognition respect. ${ }^{11}$

Not everyone will be friendly to notions such as moral injury and recognition respect. For those who do not accept these notions, the wrong that I seek to pick out with the concept of ontic injustice must be understood more simply as the wrong of being placed at risk of material and psychological harms. If a particular wife never suffers marital rape and experiences no distress at knowing that she would have no legal recourse if she were to suffer marital rape, well and good; but she has still been placed at risk of these harms in virtue of being socially constructed as a wife, and that is wrong. For someone who rejects the concepts of moral injury and recognition respect, the wrong of ontic injustice will perhaps not seem as deep as it does to one who accepts those notions, but the pragmatic benefits of having the concept of ontic injustice are exactly the same. ${ }^{12}$

The severity of an ontic injustice is the severity of the moral injury it involves, which in turn is determined by the strength of the diminishment, i.e. the strength of the impression that the individual's value has been lowered. The question of

\footnotetext{
11 The notion of recognition respect has clear connections to more overtly political conceptions of recognition (Honneth 1996; Fraser 2014), and it seems to me that the account of the wrong of ontic injustice that I have offered here could easily be developed in that direction if one were so inclined. This would yield a version of the concept that was suited to use in a certain political framework. Whilst I have no objection to this, I am here seeking to offer a version of the concept that can be incorporated into as many different political and ethical frameworks as possible. I thank Arto Laitinen for encouraging me to expand on this point.

12 I discuss these benefits in $\S 6$ below.
} 
what determines the strength of diminishment is a complex issue, and one which, due to considerations of space, I cannot fully explore here. I suspect, though, that it is a function of at least three factors. The first factor is extent to which the social treatment falls short of that to which the individual is entitled. For example, an act of extreme and humiliating violence enacts a greater diminishment than a social slight or snub. The second is the importance of the relevant moral entitlements how central they are to the conception of value (e.g. of human value) that is in question. Bodily integrity and autonomy are central to many conceptions of human value, so violations of these entitlements enact particularly strong diminishment. The third factor is the interpersonal context in which the diminishment takes place. For example, the meaning that is conveyed by someone being subjected to wrongful constraints and enablements is affected by who else is also subjected to those constraints and enablements. ${ }^{13}$ Imagine a society of total surveillance: everyone is constantly monitored, perhaps by some rotating system of mutual monitoring, and no-one is exempt. Let us further suppose that this monitoring is justified by reference to some conception of what it is to be a citizen; it is a citizen's duty to submit to monitoring for the collective good. Qua citizen, one loses the social entitlement to maintain privacy; but since everyone is socially constructed as a citizen, everyone loses this entitlement. Now, assuming that people do have a moral entitlement to greater privacy than they receive here, there is indeed a moral injury in the picture here, one that is suffered by all citizens. However, the diminishment that is enacted for any given individual is much less severe than it would be if the monitoring only applied to a small group of individuals picked out by some characteristic such as race, religion, or sexual orientation. If that were the case, it seems to me that the impression of lowered value for those individuals would be much more pronounced, and the diminishment would accordingly be stronger. There may well be further factors relevant to the strength of diminishment beyond the three I have mentioned here, but a fuller exploration must wait for another occasion.

\section{Using the Concept of Ontic Injustice}

Hopefully, at this point it is clear to the reader what ontic injustice is. My task in the rest of the paper is to show that the concept of ontic injustice can earn its philosophical keep. In this section, I'll give more detail about how the concept functions as a philosophical tool, and then, in the next section, I'll say more about what we stand to gain from adding it to our conceptual repertoire.

${ }^{13}$ I am grateful to an anonymous reviewer for this journal for encouraging me to explore this possibility. 
In order for the concept of ontic injustice to yield detailed judgements about actual cases, it needs to be combined with two further components: firstly, an account of the ontology of the social kind in question (which will draw on an account of the ontology of social kinds in general), and, secondly, an account of the moral value of the individual(s) in question and the moral demands to which this value gives rise.

With regard to the first component, making judgments about ontic injustice requires us to know whether or not a certain constraint or enablement is partly constitutive of a social kind in question. ${ }^{14}$ This is a point on which people can and do disagree, based in part on the account of social ontology to which they subscribe. Consider, for example, the phenomenon of bisexual exclusion, whereby bisexual people are often, to varying extents, denied membership in queer communities and denied access to queer spaces and queer cultural resources. This is wrong: bisexual people have a genuine interest in having access to queer communities and cultural resources, and their exclusion is unjustified. ${ }^{15}$ Now, is this a case of ontic injustice? Well, that depends on whether there is a wrongful constraint that partly constitutes the social kind bisexual. According to Ásta's conferralist account of social ontology, bisexual is here functioning as a communal kind, a social status conferred informally by other social agents in the queer community. When those agents behave towards people who they understand to be bisexual in ways that convey the impression that those people are unwelcome in queer spaces, then we can say that the social status of bisexual includes a constraint that makes it harder to be present in queer spaces. Therefore, a conferralist would say that the social kind bisexual is a site of ontic injustice. However, applying Searle's account to this case would give the opposite result, because Searle holds that conventional deontic powers are the only type of constraint/enablement that contribute to constructing social kinds. Since conventional deontic powers depend on the collective recognition of entitlements, in order for the wrongful constraint generated by bisexual exclusion to partly constitute the social kind bisexual there would need to be an explicit recognition, that is at least widely shared, to the effect that bisexuals are not entitled to access queer communities and cultural resources. Since (I take it) bisexual exclusion typically does not work like this, because it is usually a much more subtle phenomenon, Searle's account entails that the wrongful constraint generated by bisexual exclusion is not part of what constitutes the social kind bisexual, and so this is not a case of ontic injustice. This shows how judgements about putative cases of ontic injustice depend on one's understanding of the ontology of the social kind in question.

${ }^{14}$ I am grateful to an anonymous reviewer for pressing me on this point.

15 For discussions of bisexual exclusion, see, for example, Eadie (1993), Serano (2013). Sceptics about bisexual exclusion are requested to grant its existence for the sake of the example. 
With regard to the second component, what someone will think about putative cases of ontic injustice will depend on their views about what kinds of moral demands are created by different features of agents. For example, whether or not one thinks that the social kind non-human animals is a site of ontic injustice will depend on one's views on the moral entitlements of different sorts of beings. If you hold a conception of the moral value of sentient beings according to which they ought to be killed simply for the expedience of others, then you will probably think that the social kind non-human animal involves a wrongful constraint, because non-human animals are sentient beings and it is socially sanctioned to kill them simply for the expedience of others. Recall that the explanation of the wrong of ontic injustice as a moral injury does not purport to supply a general account of moral demands, because applying the concept of moral injury always involves an appeal to some independent conception of the moral value of different sorts of beings and the demands this value generates.

For reasons of space, I cannot in this paper address the question of how ontic injustice may best be combatted. However, it is important to recognise that the idea of ontic injustice does not entail that the best or only response to ontic injustice is to abolish the social kind in question. The best response could equally well be to change social ontology so that the kind is no longer constituted by wrongful constraints and enablements. Whether this is possible in a particular case depends on whether or not the wrongful constraints are a necessary part of the social kind. There is no general answer about whether this is possible; it depends on the kind in question.

For example, the marital rape exemption in England and Wales was ended in 1991: rape within marriage is now legally considered rape. Thus, the institutional kind wives has changed. Whether or not all wrongful legal constraints have been removed is another question, but it certainly seems plausible to think that all wrongful constraints could be removed without transforming the category so much that the label 'wife' is no longer appropriate. We may thus think that the social kind wife is only contingently a site of ontic injustice. In a similar spirit, Chike Jeffers holds a cultural theory of race according to which racial kinds could exist in the absence of racial oppression, since what is essential to racial kinds is not relations of dominance and subordination, but shared culture. On this view, 'a situation in which racial groups persist but in a state of equality rather than socioeconomic and Eurocentric cultural hierarchy, respecting and mutually influencing each other while remaining relatively distinct, is a coherent and admirable goal' (2013: 421). This kind of position, on which racial futures are possible and desirable, is perfectly compatible with the claim that races are currently sites of ontic injustice. ${ }^{16}$ By contrast, consider the social kind slave.

${ }^{16}$ I thank Chike for helpful discussion on this point. 
Although the constraints that constitute the kind slave are different in different institutions of slavery that have existed at different times and places, all of these institutions involve such a serious limitation of autonomy (besides frequently licensing the most extreme and brutal physical and mental harms) that it is impossible to imagine a social kind that merited the term slave that did not involve wrongful constraints. Even the least vicious form of slavery is very seriously wrongful. Therefore, it is natural to think that the social kind slave is necessarily a site of ontic injustice, and that the only appropriate response to this injustice is to abolish the kind completely. Thus, what one thinks about the response that ontic injustice merits will depend on the particular case of ontic injustice, and on one's favoured account of social ontology and, in particular, of the ways in which social categories persist through time.

\section{The Theoretical Value of Ontic Injustice}

We do not need a concept of ontic injustice to see that some constraints and enablements can be wrongful; what, then, do we gain by having a concept of ontic injustice that draws our attention specifically to the role these constraints and enablements play in social ontology? In other words, we already knew that the marital rape exemption, for example, was an injustice; what do we gain by thinking of it as an ontic injustice in particular? There are three main reasons for incorporating the concept of ontic injustice into our conceptual repertoire.

The first is that attending to the construction of social kinds highlights some specific ways in which wrongful constraints and enablements can function. This is because social kinds (as understood here) function to transmit constraints and enablements. If I am made into a wife, I come under the constraint of not being able to refuse sex with my husband. Nothing specific needs to be done to place me personally under that constraint in particular; indeed, I may not even know about it. Yet, in becoming a wife, I become subject to this constraint, because to be so constrained is part of what it is to be a wife. The operation of social ontology is thus a way by which many people come to be placed under constraints and enablements that are wrongful. Moreover, because many social kinds involve constraints and enablements that are valuable to people as well as ones that are wrongful, it can be the case that people cannot become members of social kinds that matter to them without placing themselves under wrongful constraints and enablements. This is because social kinds "bundle" constraints and enablements, so to speak. Staying with the marriage case, suppose that I want to become a certain person's legal next of kin; under certain social conditions I can only do this by becoming a wife, and hence at the cost of placing myself under an obligation to have sex with my husband whenever he chooses. Although one or both of us might protest at this - John Stuart Mill's (1851) statement preceding his marriage to 
Harriet Taylor comes to mind 17 - nothing can be done about it without changing the nature of the social kind wife, which is something that we, as two individuals, are not in position to do directly. Taking this thought even further, I might value membership in a social kind because of the meaning that kind has to me, independently of any particular constraints and enablements; perhaps I want to be a wife because of the religious significance this category holds for me. Yet I cannot access this good without placing myself under the wrongful constraint that partly constitutes the kind wife in my particular social setting. Thus, noticing how wrongful constraints and enablements can partly constitute membership in a social kind enriches our understanding of the sorts of difficulties they create for actual and potential members of the kind in question.

The second benefit of the concept of ontic injustice is that acknowledging that being made into a member of a certain kind can be wrongful in and of itself can bring clarity and insight when it comes to debates about the nature of specific social kinds. For example, it is sometimes claimed that in order to do justice to the experiences of trans people, theorists of gender ought to adopt a constraint on descriptive accounts of the ontology of gender kinds to the effect that any acceptable account must entail that all trans people are members of their identified gender. ${ }^{18}$ In other words, it is sometimes claimed that if a descriptive account of the ontology of gender kinds does not entail that all trans women are members of the social kind women and that none are members of other gender kinds (and the same, mutatis mutandis, for other genders), it should be rejected. ${ }^{19}$ Call this 'the descriptive constraint'.

For someone who believes, as I do, that misgendering someone (treating them as a gender other than that with which they identify) is seriously morally wrong and plays a major role in oppression (Bettcher 2007; Kapusta 2016), the descriptive constraint has undeniable appeal. If the nature of gender kinds is such that

\footnotetext{
${ }^{17}$ Mill writes: '[T] he whole character of the marriage relation as constituted by law being such as both [Harriet Taylor] and I entirely and conscientiously disapprove, [because] it confers upon one of the parties to the contract, legal power and control over the person, property, and freedom of action of the other party, independent of her own wishes and will; I, having no means of legally divesting myself of these odious powers (as I most assuredly would do if an engagement to that effect could be made legally binding on me), feel it my duty to put on record a formal protest against the existing law of marriage, in so far as conferring such powers; and a solemn promise never in any case or under any circumstances to use them.' (1851: 159-60)

18 Note that this claim is different from the claim that prescriptive accounts of gender terms ought to have this implication. The latter concerns how we ought to use terms like 'woman' within the context of an emancipatory political project. One proposal here is to use gender terms to refer to something other than gender social kinds in the sense usually understood in social ontology - for example, to gender identity (Jenkins 2015).

19 This claim has been made by Stephanie Kapusta (https://blog.apaonline.org/2018/08/09/transfeminism-how-trans-issues-and-feminismoverlap/) and by Rachel McKinnon (http://peasoup.typepad.com/peasoup/2016/01/ethicsdiscussions-at-pea-soup-katharine-jenkins-amelioration-and-inclusion-gender-identity-and-thehtml). I thank Stephanie for helpful discussion on this point.
} 
everyone is a member of the gender with which they identify, then all instances of misgendering are straightforwardly factually inaccurate. This seems to offer a satisfying way of capturing the sense that something is going very wrong when misgendering occurs. However, offering an account of the ontology of gender kinds as they currently exist that meets the descriptive constraint rules out the possibility of applying most accounts of social ontology to gender. For example, a proponent of conferralism would have to say that because, in a transphobic society, gender is frequently conferred in ways that depart from self-identification, many people are often made into members of gender kinds with which they don't identify. Other accounts fare similarly, because they take actual patterns of social behaviour to determine (in one way or another) the boundaries of social kinds, and current actual patterns of social behaviour frequently position trans people as members of the genders to which they were assigned at birth. Accepting the descriptive constraint therefore gives rise to serious theoretical challenges.

Recognising the phenomenon of ontic injustice helps to open up a different avenue: instead of accepting the descriptive constraint, we should acknowledge the possibility that gender kinds at present are set up in ways that exclude some trans people from membership in the gender kind with which they identify (and include them in other gender kinds), and that this social construction is itself wrongful. ${ }^{20}$ For example, in many contexts at present, genital status is treated as determining people's gender for social purposes, meaning that some trans people are prevented from navigating gendered social spaces in a way that is congruent with their gender identity (Bettcher 2007). Let us take the fictional case of Alex, a trans woman, as an example for unpacking how we can see this situation as giving rise to ontic injustice. Because Alex lives in a transphobic society in which genitals are taken to be the decisive determiner of gender, and because of the way that her body appears, she is socially constructed as a member of the social kind men. This social construction is at least partly constituted by Alex being subject to a set of constraints and enablements that includes, for example, not being permitted to use women's bathrooms (alongside many other wrongful constraints and enablements). However, I would argue, and proponents of the descriptive constraint would agree, that this social constraint is in violation of Alex's moral entitlements. ${ }^{21}$ Thus, we can say that Alex is wronged by being subject to the constraints and enablements that constitute membership in the social kind men. She suffers an ontic injustice.

Having the concept of ontic injustice to hand helps us to articulate the claim that it is a social fact that Alex is a man and not a woman - but it ought not to be. Alex is wronged by being socially constructed as a man, because the constraints and

20 Dembroff (forthcoming) adopts a similar stance on cases such as this.

${ }^{21}$ This is a substantive claim about moral entitlements, and what I say here is not intended to settle disputes about this claim. 
enablements that partly constitute kind membership are at odds with her moral entitlements. By bringing this wrong into focus, the concept of ontic injustice allows us to say that an account of the ontology of gender kinds according to which Alex is a member of the social kind men (and is not a member of the social kind women) may be, not an incorrect or wrong account of ontology, but rather a correct account of a wrongful ontology. This does justice to our sense that there is something profoundly wrong going on when Alex is categorised as a man whilst avoiding taking on the theoretical difficulties to which the descriptive constraint gives rise. ${ }^{22}$ Having the concept of ontic injustice to hand thus helps us identify an alternative to the descriptive constraint that is worthy of investigation.

The third reason that ontic injustice is a valuable philosophical tool is that it aids our understanding of various kinds of systematic oppression, such as genderbased oppression and race-based oppression. Although specific definitions vary, oppression is generally understood to be a systematic, significant, and pervasive phenomenon (Frye 1983; Young 2011; Cudd 2006). In some cases of ontic injustice, the set of constraints and enablements that (partly) constitute kind membership impose limitations that are sufficiently systematic, significant and pervasive to qualify as oppressive. I will use the term 'ontic oppression' to describe this type of ontic injustice. ${ }^{23}$ Ontic oppression should be understood as a subspecies of ontic injustice: not every case of ontic injustice is an instance of ontic oppression, for some cases of ontic injustice will feature only trivial limitations in a very narrow domain, which cannot be said to amount to oppression. In a similar vein, ontic oppression is not synonymous with oppression as such, because it may well be the case that some of the limitations or disadvantages that feature in a certain instance of oppression are not constitutive of the oppressed kind. Rather, I understand ontic oppression as capturing one facet or aspect of oppression.

There is a close connection between the concept of ontic oppression and a family of accounts of race and of gender/sex according to which race and/or gender/sex is the product of oppressive social relations. Monique Wittig, for example, writes:

It is oppression that creates sex and not the contrary.... The category of sex does not exist a priori, before all society. And as a category of dominance it cannot be a product of natural dominance but of the social dominance of women by men, for there is but social dominance. (1996, 26-27)

Similarly to Wittig, Catharine MacKinnon (1991) holds that gender is constituted by relations of sexualised domination and subordination. Charles Mills' work on the 'racial contract' (1999) expounds a roughly parallel view about race categories,

22 Of course, recognising ontic injustice does not prevent us from endorsing accounts of the ontology of gender kinds on which all trans people are members of their identified genders; it merely enables us to entertain accounts that do not have this consequence.

${ }^{23}$ See also Dembroff (forthcoming) for exploration of a similar idea. 
according to which race categories are the product of an agreement between European people to treat non-European people as 'subhuman' (having an inferior set of rights), thereby producing the category of 'White' and various categories of non-white people. Sally Haslanger (2012a) defends accounts of both race and gender according to which these kinds are defined by systematic subordination. Each of these views posits that ontological categories such as 'woman' and/or 'Black person' are constituted by oppressive constraints. The concept of ontic oppression brings into sharper focus the claim that this social construction is wrongful in and of itself.

One reason that this sharpening of focus is useful is that recognizing ontic oppression has the potential to affect how we approach emancipatory projects. The claim that social kinds are wrongful in and of themselves can function as the basis for a demand for intervention to change the nature of these kinds. If people constructed as women, for example, are wronged by being so constructed, then justice demands that the process of social construction be disrupted. The exact form that this disruption would need to take depends, of course, on the specific account of the ontology of social kinds that one favours; as Haslanger puts it, we need to understand social ontology in order to identify the 'levers for change' (2012b, 215). However, it is certainly possible that the necessary disruption may turn out to involve intervening in social processes which are not themselves obviously wrongful aside from their role in maintaining the construction of a kind which is a site of ontic oppression. The concept of ontic oppression, and of ontic injustice more broadly, can help us to make a strong case for this sort of intervention by getting a clear fix on the wrong that we are seeking to prevent ontic oppression - and laying bare its relation to the specific social processes that we are targeting in our efforts to bring about emancipatory social change.

\section{Conclusion}

I have argued that the very fact that an individual is a member of a social kind can be wrongful, because the constraints and enablements that partly constitute kind membership can be wrongful to the individual who is subjected to them. I have termed this wrong 'ontic injustice', and equated it with a moral injury, or damage to the acknowledgement of an individual's moral value. I have shown how the concept of ontic injustice must be combined with specific accounts of both social ontology and moral value in order to yield judgements about particular cases. Finally, I have argued that the concept of ontic injustice is valuable in three main ways: it draws our attention to the role played by social kinds in enacting wrongful constraints and enablements; it clarifies our options for developing accounts of the ontology of particular social kinds, such as gender kinds; and - along with the 
related concept of ontic oppression - it helps us to understand and respond to oppression.

\section{References}

Ásta. (2018) Categories We Live By: The Construction of Sex, Gender, Race, and Other Social Categories. Oxford, New York: Oxford University Press.

Bartky, Sandra. (1979) 'On Psychological Oppression'. Southwestern Journal of Philosophy, 10 (1), 190.

Bettcher, Talia Mae. (2007) 'Evil Deceivers and Make-Believers: On Transphobic Violence and the Politics of Illusion'. Hypatia, 22 (3), 43-65.

Brännmark, Johan. (2018) 'Contested Institutional Facts'. Erkenntnis, 1-8.

Calvert, Randall L. (1998) 'Rational Actors, Equilibrium, and Social Insitutions'. In Jack Knight and Itai Sened (eds.) Explaining Social Institutions (Michigan: University of Michigan Press), pp. 57-93.

Cudd, Ann E. (2006) Analyzing Oppression. New York: Oxford University Press.

Darwall, Stephen. (2004) 'Respect and the Second-Person Standpoint'. Proceedings and Addresses of the American Philosophical Association, 78 (2), 43-59.

Darwall, Stephen L. (1977) ‘Two Kinds of Respect'. Ethics, 88 (1), 36-49.

Dembroff, Robin. (Forthcoming) 'Real Talk on the Metaphysics of Gender'. Philosophical Topics.

Eadie, Jo. (1993) 'Activating Bisexuality: Toward a Bi/Sexual Politics'. In Joseph Bristow and Angelia R. Wilson (eds.) Activating Theory: Lesbian, Gay, Bisexual Politics (London: Lawrence \& Wishart), pp.139-170.

Fanon, Frantz. (2008) Black Skin, White Masks: New Edition. London: Pluto Press.

Fraser, Nancy. (2014) Justice Interruptus: Critical Reflections on the 'Postsocialist' Condition. Abingdon: Routledge.

Fricker, Miranda. (2007) Epistemic Injustice: Power and the Ethics of Knowing. Oxford: Oxford University Press.

Frye, Marilyn. (1983) 'Oppression'. In Frye (ed.) The Politics of Reality. Berkeley: Crossing Press.

Greif, Avner, and Christopher Kingston. (2011) 'Institutions: Rules or Equilibria?' In Norman Schofield and Gonzalo Caballero (eds.) Political Economy of Institutions, Democracy and Voting (Berlin, Heidelberg: Springer), pp. 1343.

Guala, Francesco, and Frank Hindriks. (2015) 'A Unified Social Ontology'. Philosophical Quarterly, 65 (259), 177-201.

Hampton, Jean. (1991) 'Correcting Harms versus Righting Wrongs: The Goal of Retribution'. UCLA Law Review, 39, 1659-1702.

Haslanger, Sally. (2012a). 'Gender and Race: (What) Are They? (What) Do We Want Them to Be?'. In Haslanger (ed.) Resisting Reality (New York: Oxford University Press), pp. 221-247.

--_. (2012b) 'Social Construction: Myth and Reality'. In Haslanger (ed.) Resisting Reality (New York: Oxford University Press), pp. 183-218. 
Honneth, Axel. (1996) Struggle for Recognition: The Moral Grammar of Social Conflicts. Cambridge: Polity.

Jeffers, Chike. (2013) 'The Cultural Theory of Race: Yet Another Look at Du Bois's "The Conservation of Races". Ethics, 123 (3), 403-26.

Jenkins, Katharine. (2015) 'Amelioration and Inclusion: Gender Identity and the Concept of Woman'. Ethics, 126 (2), 394-421.

- - - (2016). Ontic Injustice (PhD Thesis). University of Sheffield.

Kapusta, Stephanie Julia. (2016) 'Misgendering and Its Moral Contestability'. Hypatia, 31 (3), 502-19.

Kukla, Rebecca. (2014) 'Performative Force, Convention, and Discursive Injustice'. Hypatia, 29 (2), 440-57.

Mackinnon, Catherine A. (1991) Toward a Feminist Theory of the State. Cambridge, Mass.: Harvard University Press.

Mallon, Ron. (2016) The Construction of Human Kinds. New York: Oxford University Press.

Mikkola, Mari. (2016) The Wrong of Injustice: Dehumanization and Its Role in Feminist Philosophy. New York: Oxford University Press.

Mill, John Stuart. (1851/1910) 'Statement on Marriage'. In Hugh S.R. Elliot (ed.),

The Letters of John Stuart Mill (London: Longmans, Green), pp. 159-160

Mills, Charles W. (1999) The Racial Contract. Ithaca, NY: Cornell University Press.

Pettit, Philip. (1996). 'Freedom as Antipower'. Ethics, 106 (3), 576-604.

Ritchie, Katherine. (2018) 'Social Structures and the Ontology of Social Groups'. Philosophy and Phenomenological Research, online advanced view, https://doi.org/10.1111/phpr.12555.

Searle, John. (1996) The Construction of Social Reality. London: Penguin.

Searle, John. (2011) Making The Social World. Oxford: Oxford University Press.

Serano, Julia. (2013) Excluded: Making Feminist and Queer Movements More Inclusive. Berkeley, California: Seal Press.

Waldron, Jeremy. (2014) The Harm in Hate Speech. Cambridge, Mass.: Harvard University Press.

Wittig, Monique. (1996) 'The Category of Sex'. In Diana Leonard and Lisa Adkins (eds.), Sex In Question: French Materialist Feminism (London: Taylor \& Francis), pp. 25-30.

Young, Iris Marion. (2011) Justice and the Politics of Difference. Princeton, N.J: Princeton University Press. 